\title{
Extracellular Matrix Macromolecules in Tumour Microenvironment with Special Reference to Desmoplastic Reaction and the Role of Matrix Proteoglycans and Hyaluronan
}

Annele Sainio ${ }^{1}$ and Hannu Järveläinen ${ }^{1,2 *}$

${ }^{1}$ Department of Medical Biochemistry and Genetics, University of Turku, Finland

${ }^{2}$ Division of Endocrinology, Department of Medicine, Turku University Hospital, Turku, Finland

\begin{abstract}
Cancer cells create their own microenvironment via dynamically interacting with the surrounding non-malignant stromal cells and various Extracellular Matrix (ECM) macromolecules as well as with a large number of other proteins within the ECM.

The term desmoplastic reaction is used to describe a phenomenon in which ECM macromolecules including specific species of proteoglycans and hyaluronan variously accumulate around the tumour mass. The precise role of the desmoplastic reaction is not known. However, it has been proposed to represent either a defense mechanism by non-malignant host cells against invading cancer cells or to be a tumourigenesis promoting phenomenon induced by cancer cells to assist their propagation. Even an idea that desmoplastic reaction precedes the development of cancer has been introduced, further emphasizing the importance of ECM macromolecules in tumourigenesis. Here, we will discuss ECM macromolecules in tumour microenvironment focusing particularly on desmoplastic reaction and ECM proteoglycans and hyaluronan. We will also present examples of strategies how ECM macromolecules involved in desmoplastic reaction could be considered in the development of innovative oncological pharmacotherapies in the future.
\end{abstract}

Keywords: Extracellular matrix; Tumour microenvironment; Desmoplastic reaction; Cancer; Proteoglycan; Decorin; Versican; Hyaluronan

\begin{abstract}
Abbreviations: bFGF: basic Fibroblast Growth Factor; BGN: Biglycan; CD44: Hyaluronan Cell Surface Receptor CD44; CS: Chondroitin Sulfate; DCN: Decorin; DS: Dermatan Sulfate; ECM: Extracellular Matrix; EGFR: Epidermal Growth Factor Receptor; ERK1/2: Extracellular Signal-Regulated Kinase; FAK: Focal Adhesion Kinase; GAG: Glycosaminoglycan; HA: Hyaluronan; HAS1-3: Hyaluronan Synthases 1-3; HS: Heparan Sulfate; IGFIR: Insulin-Like Growth Factor-I Receptor; KS: Keratan Sulfate; LRRs: Leucine-Rich Repeats; Met: Mesenchymal-Epithelial Transition [Met] Receptor / Receptor for Hepatocyte Growth Factor; MMP: Matrix Metalloproteinase; MT1-MMP: Membrane-Type 1 Matrix Metalloproteinase; PDCD4: Programmed Cell Death 4; PG: Proteoglycan; RHAMM: Receptor for Hyaluronan-Mediated Motility; SCC: Squamous Cell Carcinoma; SLPRs: Small LeucineRich Proteoglycans; TGF $\beta$ : Transforming Growth Factor Beta; TIMP: Tissue Inhibitors of Metalloproteinase; TLRs: Toll-Like Receptors; TNC: Tenascin-C; TSP: 1, -2, Thrombospondin-1 And - 2
\end{abstract}

\section{The Extracellular Matrix of Tumour Microenvironment}

In general, there is probably no disease without changes in the composition of the ECM. The macromolecules of the ECM form a complex 3D network composed of collagens, elastin, glycoproteins, Proteoglycans (PGs) and Hyaluronan (HA) [1]. Furthermore, in the ECM there are versatile groups of additional molecules such as ECM -modifying enzymes, ECM-binding growth factors and other ECM-associated proteins [2]. The overall composition and structure of the ECM are unique and highly dynamic in each organ and tissue. Molecules of the ECM provide not only structural support but they also crucially regulate cell adhesion, migration, proliferation, differentiation, and survival [1-3]. In normal situation, molecules of the ECM control the behaviour of cells through feedback loops maintaining tissue homeostasis [1,2]. In tumours, on the other hand, there is their own microenvironment where ECM molecules variously promote tumour cell survival, growth, migration and metastasis [4]. Within the ECM there is also a rich cellular component consisting of normal fibroblasts, activated fibroblasts called myofibroblasts or cancer-associated fibroblasts, inflammatory cells and tumourigenesis promoting stem cells or their derivatives $[5,6]$. The complex interplay between the cancer cells, non-malignant host cells and various ECM molecules leads to vast activation process resulting in desmoplastic reaction which means the accumulation of ECM macromolecules such as collagens, matricellular proteins, proteinases and their inhibitors and also specific species of PGs and HA.

\section{Desmoplastic Reaction in Cancer}

The composition of tumour associated desmoplastic reaction is very similar to that of the granulation tissue $[7,8]$. The term desmoplastic reaction describes a phenomenon in which a dense fibrotic tissue rich in collagen and other ECM macromolecules including specific species of PGs and HA surrounding the tumour mass is observed $[9,10]$. This reactive stromal response is thought to

*Corresponding author: Hannu Järveläinen, Turku University Hospital Division of Endocrinology, Department of Medicine, Kiinamyllynkatu 4-8, FI20520 Turku, Finland, Tel: +358 2333 7583; Fax: +358 2230 1280; E-mail: hannu.jarvelainen@utu.fi

Received April 02, 2013; Accepted April 26, 2013; Published May 13, 2013

Citation: Sainio A, Järveläinen H (2013) Extracellular Matrix Macromolecules in Tumour Microenvironment with Special Reference to Desmoplastic Reaction and the Role of Matrix Proteoglycans and Hyaluronan. J Carcinogene Mutagene S13: 002. doi:10.4172/2157-2518.S13-002

Copyright: ( 2013 Sainio A, et al. This is an open-access article distributed unde the terms of the Creative Commons Attribution License, which permits unrestricted use, distribution, and reproduction in any medium, provided the original author and source are credited. 
be produced primarily by specified myofibroblasts which form a highly heterogeneous cell population with different phenotypes and modulate the behaviour of both tumour cells and host cells $[6,8]$. The exact role of the desmoplasmic reaction associated with cancer development is not known. However, it has been proposed to represent either a defense mechanism by normal host cells against invading cancer cells $[11,12]$ or to be a tumourigenesis promoting phenomenon induced by cancer cells to assist their propagation $[7,13]$. Furthermore, an idea that desmoplastic reaction precedes the development of cancer has been introduced $[8,14]$. Nevertheless, the desmoplastic reaction is clearly detectable in many primary and metastatic tumours including colorectal [12], liver [15], pancreatic [10,16] and prostate cancers [12] and even in some rare tumour types such as syringomatous carcinoma [17]. However, further studies are needed to better clarify the exact role of desmoplastic reaction in tumourigenesis before it is possible to fully assess whether desmoplastic reaction associated molecules might provide a target in the treatment of cancers.

\section{Extracellular Matrix Macromolecules Associated with Desmoplastic Reaction}

In the ECM, there are several individual macromolecules that have been shown to be associated with desmoplastic reaction. These molecules have various effects on cancer cells depending on both the molecule and the cancer type in which they are expressed. Overexpression of collagen types I, III, IV, V and XII create a sclerotic stroma around the cancer cell population comprising a dense fibrotic deposition typical of desmoplastic reaction $[12,18]$. In addition to this restrictive fibrotic formation, different collagen types can also have distinct functional roles. For example, the accumulation of collagen type I in pancreatic cancer has been shown to increase the malignancy of the cancer cells via increasing their proliferation, migration and survival $[19,20]$. More precisely, in pancreatic cancer is has been shown that cancer cells can increase the expression of collagen synthesis by normal pancreatic stellate cells thus providing a functional interaction between the malignant and normal cells [19]. The collagen-rich tumour environment has also been demonstrated to have a biochemical role affecting the cancer progression through the interplay between type I collagen, membrane-type 1 matrix metalloproteinase (MT1-MMP) and Transforming Growth Factor Beta (TGF- $\beta$ ) [20]. In the case of type IV collagen, its upregulation has been demonstrated to be associated with enhanced metastasis power of colorectal cancer cells to the liver [21]. Besides collagens, matricellular proteins such as thrombospondin-1 (TSP-1), -2 (TSP-2) and tenascin-C (TNC) can have altered expression patterns in different cancers [22,23]. Contrary to type I collagen, overexpression of TSP-1 has been suggested to have a protective effect on tumour progression, particularly in papillary thyroid carcinoma where the interaction of TSP-1 with one of its receptor, alpha root of beta 3 is of central importance [24]. On the other hand, tumourderived pancreatic stellate cells can promote the release of growth factors such as TSP-2 which has been shown to stimulate pancreatic cancer cell invasion [25]. Regarding TNC, its increased expression has been shown to be associated with tumour aggressiveness in medullary thyroid carcinoma [26]. In addition to collagen and matricellular proteins, also proteinases as well as their inhibitors can contribute to desmoplastic reaction.

Especially, the presence of Matrix Metalloproteinases (MMPs) and their inhibitors, namely Tissue Inhibitors Of Metalloproteinases (TIMPs) are of central importance when predicting the invasion and metastasis of cancer cells $[20,27]$. In breast cancer, it has been shown that the expression of both MMPs and TIMPs is significantly associated with the capability of tumour cells to metastasize [28,29].

Although TIMPs are usually considered to act as inhibitors and regulators of MMPs, they have also been demonstrated to possess distinct tumourigenesis promoting functions, thus further emphasizing their multifunctionality [29,30]. All the aforementioned molecules associated with desmoplastic reaction emphasize the vital interaction between the stroma and the cancer cells. This is also true for ECM PGs and HA introduced and discussed next.

\section{Extracellular Matrix Proteoglycans and their Classification}

Proteoglycans are essential macromolecules composed of a specific core protein substituted with covalently linked Glycosaminoglycan (GAGs) side chains, the hallmark of the PGs. HA is an exception; it is the only GAG synthesized in a free form lacking a protein core. GAGs are linear, negatively charged polysaccharides which exist as sulfated (Chondroitin Sulfate (CS), Dermatan Sulfate (DS), Keratan Sulfate (KS), heparin, Heparan Sulfate (HS)) and non-sulfated forms and together with the core protein create the physiological properties of each individual PG [31].

PGs such as decorin and biglycan are found in almost all extracellular matrices of tissues but some PGs seem to be highly tissue and cell specific [32]. Together with various combinations of core proteins and different GAGs, PGs have a vast diversity of biological functions.

Extracellular PGs can be classified in several ways. On the basis of their localization, three main groups of ECM PGs exist, namely matrix-accumulated PGs, Small Leucine-Rich PGs (SLRPs) and basement membrane PGs [33]. When taking into account also the size and modular composition of ECM PGs, in addition to the localization and the type of GAG carried by the PG's core protein, division to the following families can be made; SLRPs, modular PGs, and cell-surface PGs $[31,32]$. As the knowledge of the physiological functions and the pathological roles of PGs expand in time, PG classification will modify itself further.

The expression of PGs and HA is known to be significantly different in tumour tissues compared to normal ones [12,34]. In tumour tissues, the unique expression of these ECM molecules can variously modulate tumourigenesis, for example by regulating growth factor activity and thereby tumour cell proliferation and invasion [35]. Next, we will discuss the ECM PGs and HA in cancer associated desmoplastic reaction (Table 1) and review their potential roles in tumourigenesis.

\section{SLRPs in tumour microenvironment}

Small Leucine-Rich Proteoglycans (SLRPs) such as Decorin (DCN) and biglycan (BGN) are secreted PGs composed of a protein core with Leucine-Rich Repeats (LRRs) and at least one GAG side chain $[32,36]$. Both DCN and BGN contain 10 LRRs and comprise the first sub-family of SLRPs. Altogether there are five sub-families (Class I-V) with 18 known members $[31,36]$. The structure of SLRPs enables them to modulate cellular functions through interactions with other ECM proteins, various cytokines, cell surface receptors and different growth factors [37]. In addition to general effects such as modulation of adhesion, proliferation and migration, SLRPs possess also moleculespecific functions which are achieved in a cell-specific manner [31].

Although the role of SLRPs in desmoplastic reaction is not exactly 
Citation: Sainio A, Järveläinen H (2013) Extracellular Matrix Macromolecules in Tumour Microenvironment with Special Reference to Desmoplastic Reaction and the Role of Matrix Proteoglycans and Hyaluronan. J Carcinogene Mutagene S13: 002. doi:10.4172/2157-2518.S13-002

\begin{tabular}{|c|c|c|c|}
\hline & Molecule & $\begin{array}{l}\text { Core protein size } \\
(\mathrm{kDa})\end{array}$ & $\begin{array}{l}\text { GAG type (number of } \\
\text { GAGs) }\end{array}$ \\
\hline \multirow{5}{*}{ SLRPs } & Decorin & 40 & CS/DS (1) \\
\hline & Biglycan & 40 & CS/DS (1-2) \\
\hline & Asporin & 43 & none \\
\hline & Fibromodulin & 58 & KS (4) \\
\hline & Lumican & 38 & KS (2-3) \\
\hline \multirow[t]{4}{*}{ Modular PGs } & $\begin{array}{l}\text { Versican } \\
\text { (isoforms V0- } \\
\text { V4) }\end{array}$ & $\begin{array}{l}370,262,180,72 \\
115 \text { (V0-V4) }\end{array}$ & CS/DS (0-23) \\
\hline & Aggrecan & $210-250$ & CS (100) KS (30) \\
\hline & Brevican & $50,80,145$ & $\operatorname{CS}(0-5)$ \\
\hline & Perlecan & $400-467$ & $\begin{array}{l}\text { HS (3-10)/(CS, DS, hybrid } \\
\text { HS/CS, CS/DS chains or } \\
\text { GAG-free glycoprotein) }\end{array}$ \\
\hline $\mathrm{HA}^{*}$ & $\begin{array}{l}\text { Very low, low, } \\
\text { medium } \\
\text { and high HA } \\
\text { species }\end{array}$ & $\begin{array}{l}\begin{array}{l}\text { Molecular weight } \\
(\mathrm{kDa})\end{array} \\
50,300,800,2000- \\
3000\end{array}$ & $\begin{array}{l}\text { Repeating glucuronic } \\
\text { acid and } \\
\mathrm{N} \text {-acetylglucosamine } \\
\text { disaccharides }\end{array}$ \\
\hline
\end{tabular}

${ }^{*} \mathrm{HA}$ is the only GAG synthesized in a free form lacking a protein core.

Table 1: Extracellular matrix PGs and $\mathrm{HA}$ in tumour microenvironment.

known, several of them are associated with cancer development. Regarding decorin, its expression has been shown to vary in cancers. For example, in Kaposi's sarcoma DCN expression is markedly upregulated around the tumour mass (Figure 1) [38]. In contrast, in colon carcinoma the expression of DCN is reduced [39]. However, the current view is that DCN possesses antitumourigenic and antimetastatic functions via various mechanisms of action [40-43]. DCN has a recognized role in the reduction of cancer cell invasion and migration even as an aberrantly expressed nuclear localized form [44]. Specifically, DCN inhibits tumour growth by antagonizing various receptor tyrosine kinases such as Epidermal Growth Factor Receptor (EGFR) and other ErbB family members resulting in cell cycle arrest through increase in endogenous p21 [45-48]. Furthermore, analogously to EGFR signaling, DCN's interaction with mesenchymalepithelial transition (Met) receptor, i.e., receptor for hepatocyte growth factor has been shown to block signaling pathways leading to e.g. the inhibition of angiogenesis [48-51]. Decorin also sequesters multiple other growth factors 51 , particularly Transforming Growth Factor 1 (TGF-1), and thereby promotes tumour progression [51-53]. The role of DCN in tumourigenesis can also be mediated via the Insulin-Like Growth Factor-I (IGF-I) system [54]. In addition, although not well understood, DCN's interaction with Toll-Like Receptors (TLRs) has been reported to cause reduced tumour growth via immune response through Programmed Cell Death 4 (PDCD4) and microRNA-21 [55]. Antitumouric action of DCN has been observed with systemic delivery of decorin core protein [56] and with DCN transfection on cancer cells $[57,58]$.

The association of decorin's class mate, BGN, with cancer is more complicated. In several cancer types such as gastric [59] and colorectal cancers [60] decreased expression of BGN seems to be a biomarker for poorer prognosis. Furthermore, in pancreatic adenocarcinoma, increased expression of BGN is considered to prevent tumour growth and invasivity of cancer cells [61]. BGN has also been discovered to act as a signaling molecule $[62,63]$ and being capable of regulating downstream signaling events by clustering different types of cell surface receptors [64]. While BGN mediated signaling influences tumour microenvironment, the precise role of BGN in cancer is still not known. In a recent paper by Yamamoto and collegues [65], BGN was found to act as an autocrine angiogenic factor of tumour endothelial cells, thus widening the role of BGN in tumourigenesis even further.
Also other SLRPs including asporin [66,67], fibromodulin $[12,17,68]$, and lumican [69-71] have been shown to be associated with tumourigenesis - asporin and fibromodulin via their potential clinical value for applications in diagnostics and therapeutics and lumican via its antiangiogenic activity. In more detail, asporin is found to be expressed in significant amounts in pancreatic ductal adenocarcinoma tissue [66] and its concentration has been shown to be increased in the blood of men with prostate adenocarcinoma [67]. Regarding fibromodulin, it exhibits exclusive ectopic expression in B-cell chronic lymphocytic leukemia [72]. Lumican, in turn, has been shown to enhance Fas mediated endothelial cell apoptosis in vivo [71] as well as cause interference with 1 receptor activity and downregulation of MMP-14 [70].

\section{Expression of modular PGs and HA in tumour microenvironment}

Modular ECM PGs are multidomain PGs with various elongated protein modules and highly glycosylated structure [32]. They can be divided into two groups; first to hyalectans such as versican, aggrecan and brevican, and secondly to non-hyaluronan binding PGs, e.g. perlecan $[32,73]$. These ECM PGs contain a central domain that carries most of the GAGs, from three in brevican up to 100 in aggrecan, and this domain is flanked by regions that bind HA and contain C-type lectin-like domains, respectively [32,74].

From the hyalectans, versican is the most cancer associated ECM PG, as its expression is altered in most cancer types including bladder [75], colon [76], breast [77] and ovarian cancers [78]. In adenocarcinomas, versican seems to be the primary ECM PG secreted by the activated peritumoural stromal cells, e.g. myofibroblasts $[79,80]$. The role of versican in promoting [75] or inhibiting [76] cancer development is based on its vast network of interactions with other ECM molecules and cell-surface proteins including HA, multiple types of cell adhesion receptors and molecules, growth factors and their receptors and chemokines [74,81]. Versican is expressed as five isoforms (V0-V4) [77], V0 and V1 being the most prominent in cancer tissues as reviewed by Ricciardelli and collegues [82]. Isoforms V0 and V1 have been indicated e.g. in promoting glioma [83] and melanoma cell behaviour [84] towards more malignant phenotype via their capability to interact with TGF- 2 and the hyaluronan cell surface receptor CD44, respectively. Also other modular ECM PGs such as

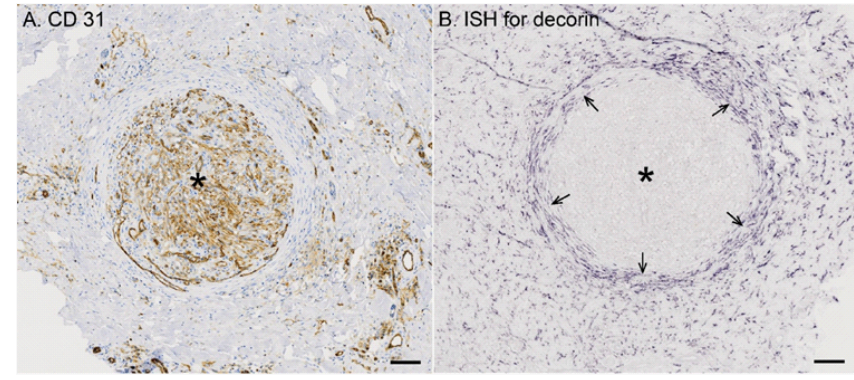

Figure 1: Proteoglycan decorin in desmoplastic reaction associated with Kaposi's sarcoma. A.Immunohistochemical staining of Kaposi's sarcoma tissue sample with an antibody to the endothelial cell marker CD31 [38]. B. In Situ Hybridization (ISH) of consecutive tissue section for decorin. Decorin ISH was performed on Kaposi's sarcoma tissue sample with human decorin antisense and sense single-stranded RNA riboprobes [38]. Positive reaction in $\mathrm{ISH}$ can be seen in purple. Note that decorin is heavily expressed in the ECM surrounding the sarcoma tissue. Asterisks in A and B indicate the tumour mass. Arrows in $B$ point to the border between the sarcoma tissue and its surrounding ECM. Scale bar in A and B, $100 \mu \mathrm{m}$. 
aggrecan [85,86] and brevican [87] have been indicated with cancer development through their differential expression in cancer compared to healthy tissue. With aggrecan, it has been shown that in laryngeal squamous cell cancers the amount of aggregable aggrecan is excessively lost which is associated with cartilage destruction and linked with progression of the cancer [86].

Furthermore, chondrosarcoma cells are known to experience altered pattern of aggrecan mRNA splicing compared to normal cartilage. This is associated with transformation of chondrocytes into malignant cells [85]. Regarding brevican, its expression is upregulated in brain tumours including astrocytoma where it represents one of the ECM molecules responsible for invasiveness of the malignant cells and thus provides potential target for treatment for cancer [87]. Furthermore, in glioma the enhanced cell adhesion and migration of cancer cells have been shown to be dependent on proteolytic cleavage of brevican via activating e.g. EGF signaling resulting in secretion and accumulation of fibronectin [88]. Concerning the HSPG perlecan, its expression has been shown to be involved directly in the tumour progression through its ability to store and capture growth factors such as basic fibroblast growth factor (bFGF) $[32,73]$. In addition, in various cancer types including melanomas, the expression of perlecan has been shown to be marker for aggressive phenotype [73].

Hyaluronan, a versatile non-sulfated GAG, which is produced by hyaluronan synthases 1-3 (HAS1-3), consists of repeating glucuronic acid and $\mathrm{N}$-acetylglucosamine disaccharides. It can be found abundantly in most tissues of the human body $[89,90]$. HA does not have a core protein but it can bind to a variety of PGs namely hyalectans via the N-terminal domains of these PGs and act as an organizer of pericellular and extracellular matrices [31,90]. There is a vast amount of evidence ascertaining the role of HA in several cancer types such as prostate [91], ovarian [92], breast [93] and thyroid cancers [94] with stromal accumulation typical for progressed and poorly differentiated tumors indicating poor prognosis.

Specifically, breast and lung cancers exhibit more pronounced HA expression in the invasion front than in central tumour areas $[95,96]$, and the metastatic score of breast cancer can even be assessed on the basis of HA metabolism [97]. The expression of HA has typically been linked with tumour progression via various mechanisms such as increased motility, invasive phenotype, proliferation and stimulation of growth factor production emphasizing a central role for HA as a modifier of tumour cell behaviour $[98,99]$. Binding of HA to its receptors, hyaladherins, e.g. CD44 and different isoforms of RHAMM [receptor for hyaluronan-mediated motility] [100,101] activates intracellular signaling leading to bidirectional information flow between the ECM and the cell genome in a phenomenon called dynamic reciprocity $[102,103]$. More precisely, CD44/HA binding leads to e.g. release of Basic Fibroblast Growth Factor (bFGF) and TGF- 1 [99] whereas RHAMM/HA interaction activates Focal Adhesion Kinase (FAK) and extracellular signal-regulated kinase (ERK1/2) [104]. More examples concerning the possible roles of $\mathrm{HA}$ in desmoplastic reaction and tumourigenesis could also be introduced.

In addition to HA, also other GAGs, namely chondroitin, dermatan, and heparan sulfates which normally exist as side chains of PGs have been shown to variously accumulate in the microenvironment of a number of tumours including breast and ovarian cancers and thereby influence tumourigenesis [105-107]. However, it is noteworthy that the accumulation of GAGs does not necessarily promote tumourigenesis but can prevent it as has been shown for heparin-like polysaccharides [106].

\section{Desmoplastic Reaction and Development of New Oncological Pharmacotherapies in the Future}

As brought up above, drastic changes in the composition of ECM macromolecules including specific species of ECM PGs and also HA can take place in tumour microenvironment. These changes can lead to the formation of fibrotic response called desmoplastic reaction which can have various effects on tumourigenesis. The fibrotic response can also drastically restrict the use of pharmacotherapies, i.e. if the drug does not reach cancer cells, it cannot kill them despite of its efficacy in cell culture conditions [108]. Fibrosis in desmoplastic reaction causes problems to the delivery of anticancer drugs particularly in pancreatic $[10,16]$ and liver cancers [15].

For example, in pancreatic cancer, the fibrotic tissue surrounding the tumour mass can account for $>80 \%$ of the tumour volume [109]. In that perspective, inhibition of the synthesis of accumulating ECM macromolecules or their degradation could assist drug availability to the target tissue. Antifibrotic therapy on pre-neoplastic diseases such as liver cirrhosis [110] and pancreatic fibrosis [111] has already been promisingly tested in animals, but their real benefits in clinical trials wait to be evaluated. Furthermore, in malignancies like pancreatic ductal carcinoma and liver cirrhosis, the desmoplastic reaction also contains vast amounts of HA resulting in exceptionally high interstitial fluid pressure in solid tumour tissue, which in turn can prevent perfusion and diffusion of small molecule therapeutics [112] Therefore, degradation of HA or restriction of its synthesis could be a rationale way to improve drug availability in these diseases. This kind of approach has already been successfully applied in the treatment of diabetes where the use of hyaluronidase can accelerate insulin exposure [113]. Also the use of 4-methylumbelliferone, a HA synthesis inhibitor has been shown to reduce HA induced fibrosis and to possess also other antitumour effects in hepatocellular carcinoma [114]. As it is natural, additional examples regarding oncological therapies that focus on ECM of tumours could be presented [115].

\section{Conclusion}

As discussed above, cancer cells create their own microenvironment. Desmoplastic reaction is a phenomenon where a dense fibrotic tissue rich in collagen and other ECM macromolecules including specific species of matrix PGs and HA around the tumour mass is observed. This reaction can either restrict or promote tumour progression. Desmoplastic reaction has even been suggested to precede tumourigenesis. Although much is already known about the possible mechanisms how individual ECM macromolecules involved in desmoplasia influence tumour cell behaviour, the importance of desmoplastic reaction as a whole in tumourigenesis still remains to be resolved. Nevertheless, targeting individual ECM macromolecules involved in desmoplastic reaction offers new promising ways to influence tumour progression via modulating e.g. growth factor activity. In the future novel drugs targeted to the microenvironment of cancers represent a direction of anticancer therapy that cannot be overlooked, especially in highly lethal cancer types such as pancreatic cancer associated with harmful desmoplasia. Furthermore, gaining better understanding of the process behind desmoplastic reaction and its influence on cancer progression would improve the development of even more effective cancer treatments.

\section{References}

1. Järveläinen H, Sainio A, Koulu M, Wight TN, Penttinen R (2009) Extracellular matrix molecules: potential targets in pharmacotherapy. Pharmacol Rev 61 198-223. 
Citation: Sainio A, Järveläinen H (2013) Extracellular Matrix Macromolecules in Tumour Microenvironment with Special Reference to Desmoplastic Reaction and the Role of Matrix Proteoglycans and Hyaluronan. J Carcinogene Mutagene S13: 002. doi:10.4172/2157-2518.S13-002

Page 5 of 7

2. Hynes RO, Naba A (2012) Overview of the matrisome--an inventory of extracellular matrix constituents and functions. Cold Spring Harb Perspect Biol 4: a004903.

3. Daley WP, Peters SB, Larsen M (2008) Extracellular matrix dynamics in development and regenerative medicine. J Cell Sci 121: 255-264.

4. Lu P, Weaver VM, Werb Z (2012) The extracellular matrix: a dynamic niche in cancer progression. J Cell Biol 196: 395-406.

5. Karnoub AE, Dash AB, Vo AP, Sullivan A, Brooks MW, et al. (2007) Mesenchymal stem cells within tumour stroma promote breast cancer metastasis. Nature 449: 557-563.

6. Desmoulière A, Guyot C, Gabbiani G (2004) The stroma reaction myofibroblast: a key player in the control of tumor cell behavior. Int J Dev Biol 48: 509-517.

7. Dvorak HF (1986) Tumors: wounds that do not heal. Similarities between tumor stroma generation and wound healing. N Engl J Med 315: 1650-1659.

8. Bissell MJ, Radisky D (2001) Putting tumours in context. Nat Rev Cancer 1 46-54

9. Vong S, Kalluri R (2011) The role of stromal myofibroblast and extracellular matrix in tumor angiogenesis. Genes Cancer 2: 1139-1145.

10. Merika EE, Syrigos KN, Saif MW (2012) Desmoplasia in pancreatic cancer Can we fight it? Gastroenterol Res Pract 2012: 781765

11. Angeli F, Koumakis G, Chen MC, Kumar S, Delinassios JG (2009) Role of stromal fibroblasts in cancer: promoting or impeding? Tumour Biol 30: 109-120.

12. Coulson-Thomas VJ, Coulson-Thomas YM, Gesteira TF, de Paula CA, Made AM, et al. (2011) Colorectal cancer desmoplastic reaction up-regulates collagen synthesis and restricts cancer cell invasion. Cell Tissue Res 346: 223-236.

13. Schäfer M, Werner S (2008) Cancer as an overhealing wound: an old hypothesis revisited. Nat Rev Mol Cell Biol 9: 628-638.

14. DeFilippis RA, Chang H, Dumont N, Rabban JT, Chen YY, et al. (2012) CD36 repression activates a multicellular stromal program shared by high mammographic density and tumor tissues. Cancer Discov 2: 826-839.

15. Kocabayoglu P, Friedman SL (2013) Cellular basis of hepatic fibrosis and its role in inflammation and cancer. Front Biosci (Schol Ed) 5: 217-230.

16. Authors Whatcott CJ, Posner RG, Von Hoff DD, Han H (2012) Desmoplasia and chemoresistance in pancreatic cancer. Desmoplasia and chemoresistance in pancreatic cancer

17. El khannoussi B, Hechlaf H, Lalya I, Oukabli M, Al Bouzidi A, et al. (2012) Syringomatous carcinoma: case report of a rare tumor entity. Pan Afr Med J 12: 76

18. Karagiannis GS, Petraki C, Prassas I, Saraon P, Musrap N, et al. (2012) Proteomic signatures of the desmoplastic invasion front reveal collagen type $\mathrm{XII}$ as a marker of myofibroblastic differentiation during colorectal cancer metastasis. Oncotarget 3: 267-285.

19. Armstrong T, Packham G, Murphy LB, Bateman AC, Conti JA, et al. (2004) Type I collagen promotes the malignant phenotype of pancreatic ductal adenocarcinoma. Clin Cancer Res 10: 7427-7437.

20. Shields MA, Dangi-Garimella S, Redig AJ, Munshi HG (2012) Biochemical role of the collagen-rich tumour microenvironment in pancreatic cancer progression. Biochem J 441: 541-552.

21. Nyström H, Naredi P, Berglund A, Palmqvist R, Tavelin B, et al. (2012) Livermetastatic potential of colorectal cancer is related to the stromal composition of the tumour. Anticancer Res 32: 5183-5191.

22. Bornstein $P$ (1995) Diversity of function is inherent in matricellular proteins: an appraisal of thrombospondin 1. J Cell Biol 130: 503-506.

23. Li X, Ma Q, Xu Q, Duan W, Lei J, et al. (2012) Targeting the cancer-stroma interaction: a potential approach for pancreatic cancer treatment. Curr Pharm Des 18: 2404-2415.

24. Patey M, Delemer B, Bellon G, Martiny L, Pluot M, et al. (1999) Immunohistochemical study of thrombospondin and its receptors alpha roo of beta 3 and CD36 in normal thyroid and in thyroid tumours. J Clin Pathol 52 : 895-900.

25. Farrow B, Berger DH, Rowley D (2009) Tumor-derived pancreatic stellate cells promote pancreatic cancer cell invasion through release of thrombospondin-2. J Surg Res 156: 155-160.
26. Koperek O, Scheuba C, Puri C, Birner P, Haslinger C, et al. (2007) Molecular characterization of the desmoplastic tumor stroma in medullary thyroid carcinoma. Int J Oncol 31: 59-67.

27. Gress TM, Müller-Pillasch F, Lerch MM, Friess H, Büchler M, et al. (1995) Expression and in-situ localization of genes coding for extracellular matrix proteins and extracellular matrix degrading proteases in pancreatic cancer. In J Cancer 62: 407-413.

28. Zhang M, Teng XD, Guo XX, Li ZG, Han JG, et al. (2012) Expression of tissue levels of matrix metalloproteinases and their inhibitors in breast cancer. Breast

29. Vizoso FJ, González LO, Corte MD, Rodríguez JC, Vázquez J, et al. (2007) Study of matrix metalloproteinases and their inhibitors in breast cancer. $\mathrm{Br} J$ Cancer 96: 903-911.

30. Jiang Y, Goldberg ID, Shi YE (2002) Complex roles of tissue inhibitors of metalloproteinases in cancer. Oncogene 21: 2245-2252.

31. Schaefer L, Schaefer RM (2010) Proteoglycans: from structural compounds to signaling molecules. Cell Tissue Res 339: 237-246.

32. lozzo RV, Murdoch AD (1996) Proteoglycans of the extracellular environment: clues from the gene and protein side offer novel perspectives in molecular diversity and function. FASEB J 10: 598-614.

33. Theocharis AD, Skandalis SS, Tzanakakis GN, Karamanos NK (2010) Proteoglycans in health and disease: novel roles for proteoglycans in malignancy and their pharmacological targeting. FEBS J 277: 3904-3923.

34. Iozzo RV, Cohen I (1993) Altered proteoglycan gene expression and the tumor stroma. Experientia 49: 447-455.

35. lozzo RV, Cohen I (1994) Altered proteoglycan gene expression and the tumo stroma. EXS 70: 199-214.

36. Schaefer L, lozzo RV (2008) Biological functions of the small leucine-rich proteoglycans: from genetics to signal transduction. J Biol Chem 283: 21305 21309.

37. Merline R, Schaefer RM, Schaefer L (2009) The matricellular functions of smal leucine-rich proteoglycans (SLRPs). J Cell Commun Signal 3: 323-335.

38. Salomäki HH, Sainio AO, Söderström M, Pakkanen S, Laine J, et al. (2008) Differential expression of decorin by human malignant and benign vascular tumors. J Histochem Cytochem 56: 639-646.

39. Augoff K, Rabczynski J, Tabola R, Czapla L, Ratajczak K, et al. (2008) Immunohistochemical study of decorin expression in polyps and carcinomas of the colon. Med Sci Monit 14: CR530-535.

40. Reed CC, Waterhouse A, Kirby S, Kay P, Owens RT, et al. (2005) Decorin prevents metastatic spreading of breast cancer. Oncogene 24: 1104-1110.

41. Goldoni S, Seidler DG, Heath J, Fassan M, Baffa R, et al. (2008) An antimetastatic role for decorin in breast cancer. Am J Pathol 173: 844-855.

42. Shintani K, Matsumine A, Kusuzaki K, Morikawa J, Matsubara T, et al. (2008) Decorin suppresses lung metastases of murine osteosarcoma. Oncol Rep 19 1533-1539.

43. Bi X, Pohl NM, Qian Z, Yang GR, Gou Y, et al. (2012) Decorin-mediated inhibition of colorectal cancer growth and migration is associated with E-cadherin in vitro and in mice. Carcinogenesis 33: 326-330.

44. Dil N, Banerjee AG (2011) A role for aberrantly expressed nuclear localized decorin in migration and invasion of dysplastic and malignant oral epithelia cells. Head Neck Oncol 3: 44 .

45. lozzo RV (1999) The biology of the small leucine-rich proteoglycans. Functional network of interactive proteins. J Biol Chem 274: 18843-18846.

46. Csordás G, Santra M, Reed CC, Eichstetter I, McQuillan DJ, et al. (2000) Sustained down-regulation of the epidermal growth factor receptor by decorin. A mechanism for controlling tumor growth in vivo. J Biol Chem 275: 32879 32887.

47. Santra M, Eichstetter I, lozzo RV (2000) An anti-oncogenic role for decorin. Down-regulation of ErbB2 leads to growth suppression and cytodifferentiation of mammary carcinoma cells. J Biol Chem 275: 35153-35161.

48. Buraschi S, Neill T, Owens RT, Iniguez LA, Purkins G, et al. (2012) Decorin protein core affects the global gene expression profile of the tumo microenvironment in a triple-negative orthotopic breast carcinoma xenograft model. PLoS One 7: e45559. 
Citation: Sainio A, Järveläinen H (2013) Extracellular Matrix Macromolecules in Tumour Microenvironment with Special Reference to Desmoplastic Reaction and the Role of Matrix Proteoglycans and Hyaluronan. J Carcinogene Mutagene S13: 002. doi:10.4172/2157-2518.S13-002

Page 6 of 7

49. Järveläinen H, Puolakkainen P, Pakkanen S, Brown EL, Höök M, et al. (2006) A role for decorin in cutaneous wound healing and angiogenesis. Wound Repair Regen 14: 443-452.

50. Goldoni S, Humphries A, Nyström A, Sattar S, Owens RT, et al. (2009) Decorin is a novel antagonistic ligand of the Met receptor. J Cell Biol 185: 743-754.

51. Neill T, Painter H, Buraschi S, Owens RT, Lisanti MP, et al. (2012) Decorin antagonizes the angiogenic network: concurrent inhibition of Met, hypoxia inducible factor $1 \hat{I} \pm$, vascular endothelial growth factor $A$, and induction of thrombospondin-1 and TIMP3. J Biol Chem 287: 5492-5506.

52. Stover DG, Bierie B, Moses HL (2007) A delicate balance: TGF-beta and the tumor microenvironment. J Cell Biochem 101: 851-861.

53. Massagué J (2008) TGFbeta in Cancer. Cell 134: 215-230.

54. Morrione A, Neill T, lozzo RV (2013) Dichotomy of decorin activity on the insulin-like growth factor-I system. FEBS $\mathrm{J}$.

55. Merline R, Moreth K, Beckmann J, Nastase MV, Zeng-Brouwers J, et al. (2011) Signaling by the matrix proteoglycan decorin controls inflammation and cancer through PDCD4 and MicroRNA-21. Sci Signal 4: ra75.

56. Seidler DG, Goldoni S, Agnew C, Cardi C, Thakur ML, et al. (2006) Decorin protein core inhibits in vivo cancer growth and metabolism by hindering epidermal growth factor receptor function and triggering apoptosis via caspase-3 activation. J Biol Chem 281: 26408-26418.

57. Pucci-Minafra I, Cancemi P, Di Cara G, Minafra L, Feo S, et al. (2008) Decorin transfection induces proteomic and phenotypic modulation in breast cancer cells 8701-BC. Connect Tissue Res 49: 30-41.

58. Boström P, Sainio A, Kakko T, Savontaus M, Söderström M, et al. (2013) Localization of decorin gene expression in normal human breast tissue and in benign and malignant tumors of the human breast. Histochem Cell Biol 139: $161-171$.

59. Wang B, Li GX, Zhang SG, Wang Q, Wen YG, et al. (2011) Biglycan expression correlates with aggressiveness and poor prognosis of gastric cancer. Exp Biol Med (Maywood) 236: 1247-1253.

60. Gu X, Ma Y, Xiao J, Zheng H, Song C, et al. (2012) Up-regulated biglycan expression correlates with the malignancy in human colorectal cancers. Clin Exp Med 12: 195-199.

61. Aprile G, Avellini C, Reni M, Mazzer M, Foltran L, et al. (2013) Biglycan expression and clinical outcome in patients with pancreatic adenocarcinoma. Tumour Biol 34: 131-137.

62. Schaefer L, Babelova A, Kiss E, Hausser HJ, Baliova M, et al. (2005) The matrix component biglycan is proinflammatory and signals through Toll-like receptors 4 and 2 in macrophages. J Clin Invest 115: 2223-2233.

63. Berendsen AD, Fisher LW, Kilts TM, Owens RT, Robey PG, et al. (2011) Modulation of canonical Wnt signaling by the extracellular matrix component biglycan. Proc Natl Acad Sci U S A 108: 17022-17027.

64. Nastase MV, Young MF, Schaefer L (2012) Biglycan: a multivalent proteoglycan providing structure and signals. J Histochem Cytochem 60: 963-975.

65. Yamamoto K, Ohga N, Hida Y, Maishi N, Kawamoto T, et al. (2012) Biglycan is a specific marker and an autocrine angiogenic factor of tumour endothelial cells. Br J Cancer 106: 1214-1223.

66. Turtoi A, Musmeci D, Wang Y, Dumont B, Somja J, et al. (2011) Identification of novel accessible proteins bearing diagnostic and therapeutic potential in human pancreatic ductal adenocarcinoma. J Proteome Res 10: 4302-4313.

67. Klee EW, Bondar OP, Goodmanson MK, Dyer RB, Erdogan S, et al. (2012) Candidate serum biomarkers for prostate adenocarcinoma identified by mRNA differences in prostate tissue and verified with protein measurements in tissue and blood. Clin Chem 58: 599-609.

68. Mikaelsson E, Danesh-Manesh AH, Lüppert A, Jeddi-Tehrani M, Rezvany MR, et al. (2005) Fibromodulin, an extracellular matrix protein: characterization of its unique gene and protein expression in B-cell chronic lymphocytic leukemia and mantle cell lymphoma. Blood 105: 4828-4835.

69. Brézillon S, Venteo L, Ramont L, D'Onofrio MF, Perreau C, et al. (2007) Expression of lumican, a small leucine-rich proteoglycan with antitumour activity, in human malignant melanoma. Clin Exp Dermatol 32: 405-416.

70. Niewiarowska J, Brézillon S, Sacewicz-Hofman I, Bednarek R, Maquart FX, et al. (2011) Lumican inhibits angiogenesis by interfering with $\hat{I} \pm 2 \hat{l}^{2} 1$ receptor activity and downregulating MMP-14 expression. Thromb Res 128: 452-457.
71. Williams KE, Fulford LA, Albig AR (2010) Lumican reduces tumor growth via induction of fas-mediated endothelial cell apoptosis. Cancer Microenviron 4 115-126.

72. El-Hamid Hassan DA, Mohamed Samy R, Abd-Elrahim OT, Sabry Salib C (2011) Study of fibromodulin gene expression in B-cell chronic lymphocytic leukemia. J Egypt Natl Canc Inst 23: 11-15.

73. lozzo RV (1998) Matrix proteoglycans: from molecular design to cellular function. Annu Rev Biochem 67: 609-652.

74. Wu YJ, La Pierre DP, Wu J, Yee AJ, Yang BB (2005) The interaction of versican with its binding partners. Cell Res 15: 483-494.

75. Said N, Sanchez-Carbayo M, Smith SC, Theodorescu D (2012) RhoGDI2 suppresses lung metastasis in mice by reducing tumor versican expression and macrophage infiltration. J Clin Invest 122: 1503-1518.

76. de Wit M, Belt EJ, Delis-van Diemen PM, Carvalho B, Coupé VM, et al. (2012) Lumican and Versican Are Associated with Good Outcome in Stage II and III Colon Cancer. Ann Surg Oncol

77. Kischel P, Waltregny D, Dumont B, Turtoi A, Greffe Y, et al. (2010) Versican overexpression in human breast cancer lesions: known and new isoforms for stromal tumor targeting. Int J Cancer 126: 640-650.

78. Ghosh S, Albitar L, LeBaron R, Welch WR, Samimi G, et al. (2010) Upregulation of stromal versican expression in advanced stage serous ovarian cancer. Gynecol Oncol 119: 114-120.

79. Kodama J, Hasengaowa, Kusumoto T, Seki N, Matsuo T, et al. (2007) Versican expression in human cervical cancer. Eur J Cancer 43: 1460-1466.

80. Kodama J, Hasengaowa, Kusumoto T, Seki N, Matsuo T, et al. (2007) Prognostic significance of stromal versican expression in human endometrial cancer. Ann Oncol 18: 269-274.

81. Wight TN (2002) Versican: a versatile extracellular matrix proteoglycan in cell biology. Curr Opin Cell Biol 14: 617-623.

82. Ricciardelli C, Sakko AJ, Ween MP, Russell DL, Horsfall DJ (2009) The biological role and regulation of versican levels in cancer. Cancer Metastasis Rev 28: 233-245.

83. Arslan F, Bosserhoff AK, Nickl-Jockschat T, Doerfelt A, Bogdahn U, et al (2007) The role of versican isoforms V0/V1 in glioma migration mediated by transforming growth factor-beta2. Br J Cancer 96: 1560-1568.

84. Hernández D, Miquel-Serra L, Docampo MJ, Marco-Ramell A, Bassols $A$ (2011) Role of versican V0/V1 and CD44 in the regulation of human melanoma cell behavior. Int J Mol Med 27: 269-275.

85. Matsui Y, Araki N, Tsuboi H, Tsumaki N, Nakata K, et al. (2002) Differentia expression of aggrecan mRNA isoforms by chondrosarcoma cells. Anticancer Res 22: 4169-4172.

86. Skandalis SS, Theocharis AD, Vynios DH, Papageorgakopoulou N, Hjerpe A, et al. (2006) Cartilage aggrecan undergoes significant compositional and structural alterations during laryngeal cancer. Biochim Biophys Acta 1760 1046-1053.

87. Varga I, Hutóczki G, Szemcsák CD, Zahuczky G, Tóth J, et al. (2012) Brevican, neurocan, tenascin- $C$ and versican are mainly responsible for the invasiveness of low-grade astrocytoma. Pathol Oncol Res 18: 413-420.

88. Hu B, Kong LL, Matthews RT, Viapiano MS (2008) The proteoglycan brevican binds to fibronectin after proteolytic cleavage and promotes glioma cell motility. J Biol Chem 283: 24848-24859.

89. Weigel PH, Hascall VC, Tammi M (1997) Hyaluronan synthases. J Biol Chem 272: $13997-14000$

90. Evanko SP, Tammi MI, Tammi RH, Wight TN (2007) Hyaluronan-dependent pericellular matrix. Adv Drug Deliv Rev 59: 1351-1365.

91. Lipponen P, Aaltomaa S, Tammi R, Tammi M, Agren U, et al. (2001) High stromal hyaluronan level is associated with poor differentiation and metastasis in prostate cancer. Eur J Cancer 37: 849-856.

92. Anttila MA, Tammi RH, Tammi MI, Syrjänen KJ, Saarikoski SV, et al. (2000) High levels of stromal hyaluronan predict poor disease outcome in epithelia ovarian cancer. Cancer Res 60: 150-155.

93. Auvinen P, Tammi R, Parkkinen J, Tammi M, Agren U, et al. (2000) Hyaluronan in peritumoral stroma and malignant cells associates with breast cancer spreading and predicts survival. Am J Pathol 156: 529-536. 
Citation: Sainio A, Järveläinen H (2013) Extracellular Matrix Macromolecules in Tumour Microenvironment with Special Reference to Desmoplastic Reaction and the Role of Matrix Proteoglycans and Hyaluronan. J Carcinogene Mutagene S13: 002. doi:10.4172/2157-2518.S13-002

Page 7 of 7

94. Böhm J, Niskanen L, Tammi R, Tammi M, Eskelinen M, et al. (2002) Hyaluronan expression in differentiated thyroid carcinoma. J Pathol 196: 180-185.

95. Bertrand P, Girard N, Delpech B, Duval C, d'Anjou J, et al. (1992) Hyaluronan (hyaluronic acid) and hyaluronectin in the extracellular matrix of human breast carcinomas: comparison between invasive and non-invasive areas. Int $J$ Cancer 52: 1-6.

96. Ponting J, Kumar S, Pye D (1993) Colocalization of hyaluronan and hyaluronectin in normal and neoplastic breast tissues. Int J Oncol 2: 889-893.

97. El-Mezayen HA, Toson el-SA, Darwish H, Metwally FM (2013) Development of a novel metastatic breast cancer score based on hyaluronic acid metabolism. Med Oncol 30: 404

98. Tammi RH, Kultti A, Kosma VM, Pirinen R, Auvinen P, et al. (2008) Hyaluronan in human tumors: pathobiological and prognostic messages from cellassociated and stromal hyaluronan. Semin Cancer Biol 18: 288-295.

99. Sironen RK, Tammi M, Tammi R, Auvinen PK, Anttila M, et al. (2011) Hyaluronan in human malignancies. Exp Cell Res 317: 383-391.

100. Ahrens T, Assmann V, Fieber C, Termeer C, Herrlich P, et al. (2001) CD44 is the principal mediator of hyaluronic-acid-induced melanoma cell proliferation. $\mathrm{J}$ Invest Dermatol 116: 93-101.

101. Turley EA, Noble PW, Bourguignon LY (2002) Signaling properties of hyaluronan receptors. J Biol Chem 277: 4589-4592.

102. Lelièvre SA, Bissell MJ (1998) Communication between the cell membrane and the nucleus: role of protein compartmentalization. J Cell Biochem Suppl 30-31: 250-63.

103. Schultz GS, Davidson JM, Kirsner RS, Bornstein P, Herman IM (2011) Dynamic reciprocity in the wound microenvironment. Wound Repair Regen 19: 134-148.

104. Kouvidi K, Berdiaki A, Nikitovic D, Katonis P, Afratis N, et al. (2011) Role of receptor for hyaluronic acid-mediated motility (RHAMM) in low molecular weight hyaluronan (LMWHA)-mediated fibrosarcoma cell adhesion. J Biol Chem 286: 38509-38520.

105. Prinz RD, Willis CM, Viloria-Petit A, Klüppel M (2011) Elimination of breast tumor-associated chondroitin sulfate promotes metastasis. Genet Mol Res 10: 3901-3913.
106. Pollari S, Käkönen RS, Mohammad KS, Rissanen JP, Halleen JM, et al (2012) Heparin-like polysaccharides reduce osteolytic bone destruction and tumor growth in a mouse model of breast cancer bone metastasis. Mol Cancer Res 10: 597-604.

107.Vallen MJ, Massuger LF, ten Dam GB, Bulten J, van Kuppevelt TH (2012) Highly sulfated chondroitin sulfates, a novel class of prognostic biomarkers in ovarian cancer tissue. Gynecol Oncol 127: 202-209.

108. Yu M, Tannock IF (2012) Targeting tumor architecture to favor drug penetration: a new weapon to combat chemoresistance in pancreatic cancer? Cancer Cell 21: 327-329.

109. Erkan M, Reiser-Erkan C, Michalski CW, Kleeff J (2010) Tumor microenvironment and progression of pancreatic cancer. Exp Oncol 32: 128131.

110. Sato Y, Murase K, Kato J, Kobune M, Sato T, et al. (2008) Resolution of liver cirrhosis using vitamin A-coupled liposomes to deliver siRNA against a collagen-specific chaperone. Nat Biotechnol 26: 431-442.

111. Ishiwatari H, Sato $Y$, Murase K, Yoneda A, Fujita R, et al. (2012) Treatmen of pancreatic fibrosis with siRNA against a collagen-specific chaperone in vitamin A-coupled liposomes. Gut.

112. Provenzano PP, Cuevas C, Chang AE, Goel VK, Von Hoff DD, et al. (2012) Enzymatic targeting of the stroma ablates physical barriers to treatment of pancreatic ductal adenocarcinoma. Cancer Cell 21: 418-429.

113. Morrow L, Muchmore DB, Hompesch M, Ludington EA, Vaughn DE (2013) Comparative pharmacokinetics and insulin action for three rapid-acting insulin analogs injected subcutaneously with and without hyaluronidase. Diabetes Care 36: 273-275.

114. Piccioni F, Malvicini M, Garcia MG, Rodriguez A, Atorrasagasti C, et al. (2012) Antitumor effects of hyaluronic acid inhibitor 4-methylumbelliferone in an orthotopic hepatocellular carcinoma model in mice. Glycobiology 22: 400-410.

115. Chargari C, Clemenson C, Martins I, Perfettini JL, Deutsch E (2013) Understanding the functions of tumor stroma in resistance to ionizing radiation: Emerging targets for pharmacological modulation. Drug Resist Updat .

This article was originally published in a special issue, Cell-Extracellular Matrix Interactions in Carcinogenesis handled by Editor(s). Dr. Claudio Luparello, University of Palermo, Italy 